\title{
20 ANOS DE ENGENHARIA FÍSICA NO BRASIL
}

DOI: 10.37702/2175-957X.COBENGE.2021.3580

Luis Fernando Magnanini de Almeida - almeida@ufu.br Universidade Federal de Uberlândia

Rua 20, 1600, Tupã 1600

38304-402 - Ituiutaba - MG

Raphael Fortes Infante Gomes - raphael.gomes@unila.edu.br

UNILA

AVENIDA TANCREDO NEVES 5057

85867-633 - FOZ DO IGUAÇU - PR

Jefferson Esquina Tsuchida - jefferson.tsuchida@ufla.br

Universidade Federal de Lavras

Rua Projetada um 27

37202-764 - Lavras - MG

Cristiano Krug - cristiano.krug@ufrgs.br

UFRGS

Av. Bento Gonçalves, 9500

91509-900 - Porto Alegre - RS

Fernando Manuel Araújo Moreira - faraujo@df.ufscar.br

Universidade Federal de São Carlos

Rodovia Washington Luís km 23

13565-905 - São Carlos - SP

José Marques Póvoa - jose.povoa@gmail.com

UFSCar aposentado

Rua Episcopal 2110

13560-049 - São Carlos - SP

Resumo: O presente artigo analisa a consolidação da carreira de Engenharia Física no Brasil ao longo das duas primeiras décadas contabilizadas a partir do ano de criação do curso (1999-2020). Foram revisados os antecedentes e as motivações que fomentaram a sua concepção e o direcionamento para uma 
formação transdisciplinar, e analisada a evolução desta carreira com base nas informações disponíveis sobre a área e em dois estudos que abordaram a atuação profissional dos egressos no país. No fim, são discutidas as limitações e os estudos futuros que concernem às perspectivas da carreira de Engenharia Física no Brasil, comprovando que a filosofia de "aprender a aprender" e a proposta de formar profissionais multiespecialistas têm sido logradas com êxito.

Palavras-chave: Engenharia Física; Ciência; Carreira; Transdisciplinaridade; Graduados 


\section{ANOS DE ENGENHARIA FÍSICA NO BRASIL}

\section{INTRODUÇÃO}

O curso de graduação em Engenharia Física está presente em diversos países. Sua criação ocorreu há mais de um século, e o primeiro curso a formar engenheiros dessa especialidade foi o da Universidade de Oklahoma, instituído em 1924. Atualmente, só nos Estados Unidos da América (EUA) existem mais de cinquenta cursos de Engenharia Física (lá denominada "Engineering Physics" ou "Engineering Science"). O curso está presente inclusive nas cinco universidades mais renomadas em Engenharia (Cornell, Caltech, University of Illinois/Urbana-Champaign, UC Berkeley e Stanford). Ainda na América do Norte, o curso é oferecido em diversas universidades do México (por exemplo, na Universidad Autónoma Metropolitana) e do Canadá (McMaster, British Columbia, Politécnico de Montréal, entre outras). Também há numerosos exemplos na América do Sul (Colômbia, Chile, Peru, entre outras), na Europa e na Ásia. Ao todo, já foram identificados mais de duzentos cursos de Engenharia Física no mundo. No artigo "Engineering Physics: a unique field", Robert St. John resumiu (ST. JOHN, 1976):

"O Engenheiro Físico cobre a distância entre (...) o Físico, a quem interessa o conhecimento pelo próprio conhecimento, e o Engenheiro, a quem interessa a aplicação dos princípios básicos na solução de problemas práticos dentro de uma disciplina particular da Engenharia. (...) Pela natureza particular do seu treinamento e desenvolvimento, terá a flexibilidade para contribuir significativamente em muitas disciplinas da Engenharia. Deverá ser particularmente valioso no estabelecimento de um vínculo de comunicação entre as diversas disciplinas da Engenharia, assim como entre as da Engenharia e as da Física".

A Universidade Federal de São Carlos (UFSCar) introduziu o curso no Brasil em 1999, tendo como objetivo principal formar engenheiros multiespecialistas, que tivessem como principal característica a ênfase nas ciências básicas: Física, Química e Matemática (ARAÚJO-MOREIRA e PÓVOA, 2000; ARAÚJO-MOREIRA, 2014). Ao longo das duas décadas seguintes, novos cursos foram criados em praticamente todas as regiões do país. Atualmente, a formação é oferecida em 12 Universidades públicas, com um total de 441 vagas anuais registradas no sistema e-MEC (MEC, 2021).

Este trabalho tem por objetivo mostrar a evolução ocorrida nos primeiros 20 anos de existência do curso de Engenharia Física no Brasil, destacando os fatores que motivaram a sua criação, tais quais os constantes desenvolvimentos e mudanças tecnológicas, a busca por uma formação transdisciplinar e a necessidade de um bom domínio dos fundamentos e das ciências básicas. Torna-se evidente que estes quesitos foram intensificados nos últimos anos através de estudos sobre a inserção dos egressos no mercado, confirmando a importância de profissionais desta área no cenário nacional de Engenharia no século XXI.

$\mathrm{Na}$ seção seguinte, são apresentados os antecedentes e as motivações para a criação do curso de Engenharia Física no Brasil. Em seguida, são descritos os métodos utilizados no trabalho para abordar a evolução do curso ao longo das duas primeiras décadas, por meio de análises descritivas e históricas desse intervalo e das perspectivas e tendências para os próximos anos. Por fim, o trabalho discute as limitações e os estudos futuros que concernem às perspectivas da carreira de Engenharia Física no Brasil. 


\section{ANTECEDENTES E MOTIVAÇÕES PARA A CRIAÇÃO DO CURSO DE ENGENHARIA FÍSICA NO BRASIL}

O curso de Engenharia Física teve seu Ato de Criação registrado no dia 20/10/1999 pela Universidade Federal de São Carlos (UFSCar) e iniciou suas atividades em 28/02/2000. No contexto de sua criação havia uma ampla discussão sobre qual seria o perfil dos egressos, destacando-se a necessidade de "formar pessoal capaz de criar conhecimentos", "aumento do valor agregado" dos produtos nacionais, "existência de mão de obra altamente qualificada, em particular, de engenheiros" e "desenvolvimento local de produtos" (PÓVOA e ARAÚJO-MOREIRA, 2003).

Um dos expoentes dessa discussão foi o subprograma de Reengenharia do Ensino de Engenharia (REENGE), o qual estava inserido no Programa de Desenvolvimento das Engenharias (PRODENGE), que pode ser considerado um dos motivadores para a introdução do curso de Engenharia Física no Brasil (PÓVOA e ARAÚJO-MOREIRA, 2003).

A origem do projeto REENGE remonta à reforma norte-americana idealizada pela National Science Foundation (NSF), cujas propostas seguem a perspectiva de maior integração do setor educacional de Engenharia com o setor produtivo. No Brasil, constatase que ocorreu a mobilização de entidades ligadas ao campo das Engenharias no início da década de 1990, que tinha por propósito discutir e implementar ações com o intuito de reformar a Engenharia Brasileira, com destaque para a Associação Brasileira de Educação em Engenharia (ABENGE) e o Conselho Federal de Engenharia e Arquitetura (CONFEA). Ambas as instituições realizaram uma ampla pesquisa de âmbito nacional ao consultar 120 especialistas das áreas de engenharia existentes em diversas regiões do país, buscando (definir) diretrizes para orientar a formação desses profissionais e supervisionar suas atuações frente aos desafios do início do século XXI (ARANTES, 2002).

Nesse contexto de redirecionamento na formação de engenheiros, buscou-se criar um curso com objetivo formar multiespecialistas a partir de uma forte ênfase nas ciências básicas (Física, Química e Matemática) sem perder de vista o seu lado aplicado, permitindo a esses profissionais "aprender a aprender" e de absorver as necessidades da empresa e a busca/proposição de soluções (ARAÚJO-MOREIRA e PÓVOA, 2000).

\section{MÉTODO DE PESQUISA}

O presente trabalho utiliza uma abordagem majoritariamente quantitativa, através da análise secundária de dados de consultas à plataforma e-MEC e ao site do Ministério da Educação (MEC, 2021), das informações provenientes do Instituto Nacional de Pesquisas Educacionais Anísio Teixeira (INEP, 2021), do levantamento estatístico sobre a atuação profissional dos egressos do curso de Engenharia Física da UFSCar (FORTES e SANDOVAL, 2018), e de um levantamento estatístico de profissionais oriundos de todos os cursos de Engenharia Física do país que possuíam egressos (ENFI WIKI, 2020).

Para as seções de organização, resumo, interpretação e análise de dados foram utilizadas técnicas da estatística descritiva (MONTGOMERY e RUNGER, 2016) com o apoio do software Microsoft Exce/ß.

\section{ANOS DE ENGENHARIA FÍSICA NO BRASIL}

Esta seção se inicia abordando a expansão dos cursos de graduação em Engenharia Física no Brasil. Na sequência, são apresentados um levantamento dos dados referentes aos profissionais oriundos da UFSCar (até o ano de 2018) e de todas as universidades que 
possuíam egressos no país até o ano de 2020. Em paralelo, é feita uma breve análise sobre a criação do primeiro curso de pós-graduação em Engenharia Física no país.

\subsection{Expansão dos cursos de graduação}

O sucesso da criação do primeiro curso de Engenharia Física na UFSCar estimulou a abertura de mais de uma dezena de cursos de graduação similares em todas as regiões do Brasil, com exceção da Nordeste, contudo, essa conta com a única pós-graduação nacional na área. O Quadro 1 lista os cursos ativos no país em 2021 (organizados em ordem cronológica de funcionamento), indicando as subsequentes categorias administrativas e as respectivas datas de início das atividades e ao ato de criação.

Quadro 1 - Cursos de Engenharia Física ativos no Brasil em 2021.

\begin{tabular}{|c|c|c|c|c|c|}
\hline Instituição (IES) & Sigla & $\begin{array}{c}\text { Categoria } \\
\text { Administrativa }\end{array}$ & Início & Ato de Criação & $\begin{array}{c}\text { Vagas } \\
\text { anuais }\end{array}$ \\
\hline $\begin{array}{c}\text { Universidade Federal de } \\
\text { São Carlos }\end{array}$ & UFSCAR & Pública Federal & $28 / 02 / 2000$ & $20 / 10 / 1999$ & 40 \\
\hline $\begin{array}{c}\text { Universidade Federal do } \\
\text { Rio Grande do Sul }\end{array}$ & UFRGS & Pública Federal & $07 / 08 / 2009$ & $07 / 08 / 2009$ & 36 \\
\hline $\begin{array}{c}\text { Universidade Estadual } \\
\text { de Mato Grosso do Sul }\end{array}$ & UEMS & Pública Estadual & $01 / 02 / 2010$ & - & 50 \\
\hline $\begin{array}{c}\text { Universidade Federal do } \\
\text { Oeste do Pará }\end{array}$ & UFOPA & Pública Federal & $01 / 03 / 2011$ & $26 / 02 / 2013$ & 40 \\
\hline $\begin{array}{c}\text { Universidade de } \\
\text { São Paulo }\end{array}$ & USP & Pública Estadual & $01 / 01 / 2012$ & $28 / 06 / 2011$ & 40 \\
\hline $\begin{array}{c}\text { Universidade Federal de } \\
\text { Goiás }\end{array}$ & UFG & Pública Federal & $04 / 02 / 2013$ & $28 / 09 / 2012$ & 25 \\
\hline $\begin{array}{c}\text { Universidade Federal da } \\
\text { Integração Latino- } \\
\text { Americana }\end{array}$ & UNILA & Pública Federal & $02 / 03 / 2015$ & $04 / 04 / 2014$ & 50 \\
\hline $\begin{array}{c}\text { Universidade Federal } \\
\text { dos Vales do } \\
\text { Jequitinhonha e Mucuri }\end{array}$ & UFVJM & Pública Federal & $23 / 10 / 2017$ & $06 / 09 / 2013$ & 80 \\
\hline $\begin{array}{c}\text { Universidade Federal de } \\
\text { Lavras }\end{array}$ & UFLA & Pública Federal & $20 / 08 / 2018$ & $25 / 09 / 2013$ & 50 \\
\hline $\begin{array}{c}\text { Universidade Estadual } \\
\text { de Campinas }\end{array}$ & UNICAMP & Pública Estadual & - & $2016^{* *}$ & 15 \\
\hline $\begin{array}{c}\text { Instituto Tecnológico da } \\
\text { Aeronáutica*** }\end{array}$ & ITA & Pública Federal & - & $06 / 04 / 2017^{* * * *}$ & $\mathrm{NI}$ \\
\hline $\begin{array}{c}\text { Universidade Federal de } \\
\text { Mato Grosso do Sul }\end{array}$ & UFMS & Pública Federal & $07 / 01 / 2019$ & $09 / 07 / 2018$ & 30 \\
\hline
\end{tabular}

Fonte: Adaptado de MEC (2021). Legenda: * Presente dentro do curso 51. ${ }^{* *}$ Data do PPC do curso. ${ }^{* * \star}$ Fornecido dentro do Programa de formação complementar como (Minor), ${ }^{* * * *}$ Data da ata da Congregação que aprovou a criação.

O segundo curso foi inaugurado na Universidade Federal do Rio Grande do Sul (UFRGS). Sua criação ocorreu quase uma década após o início do primeiro curso, o qual já contava com cinco turmas de egressos. Já na segunda década do século XXI, verificase que houve uma expansão acelerada com a abertura de dez novos cursos de graduação, sendo oito exclusivamente de Engenharia Física, uma formação complementar (minor) criada dentro do Instituto Tecnológico da Aeronáutica, e uma especialização dentro do curso 51 da Universidade Estadual de Campinas (UNICAMP) sob a nomenclatura de Engenharia Física, que disponibilizava vagas para as respectivas ênfases em Optoeletrônica (cinco) e Produção Tecnológica (dez).

Com relação à distribuição geográfica, constata-se que há uma concentração majoritária de cursos na região Centro-Sul do Brasil. Neste sentido, São Paulo apresenta- 
se como o estado que oferece mais opções com quatro universidades (UFSCar, UNICAMP, USP e ITA). A segunda colocação é ocupada pelos estados de Minas Gerais (UFLA e UFVJM) e Mato Grosso do Sul (UEMS e UFMS), cada um com dois cursos. Completam esta lista os estados localizados nas regiões Centro-Sul (UNILA e UFRGS), Centro-Oeste (UFG) e Norte (UFOPA). Vale destacar que todos são ofertados por Instituições de Ensino Superior (IES) públicas, sendo 9 federais e 3 estaduais (conforme ilustrado na Fig. 1, à esquerda).

Ao analisar a oferta de vagas anuais, observa-se um padrão distinto do anterior, liderado pelo estado de Minas Gerais (130 vagas), seguido por São Paulo (96 vagas), Mato Grosso do Sul (80 vagas), Paraná (50 vagas), Pará (40 vagas), Rio Grande do Sul (36 vagas) e Goiás (25 vagas). Logo, há uma oferta conjunta de 456 vagas anuais, sendo 441 em cursos de Engenharia Física e 15 adicionais (nas ênfases da UNICAMP). Ressalta-se que não foi encontrado o número de vagas disponibilizados na formação complementar ofertada pelo ITA e, portanto, as mesmas não foram consideradas para efeitos da análise. Estes números comprovam o evidente potencial de crescimento da carreira no país, tanto em relação ao número de estados que oferecem o curso, quanto em relação à oferta de vagas anuais. A Fig. 1 ilustra a distribuição destas vagas no cenário nacional.

Figura 1 - Número de Cursos por estado (esquerda) e vagas anuais por estado (direita).

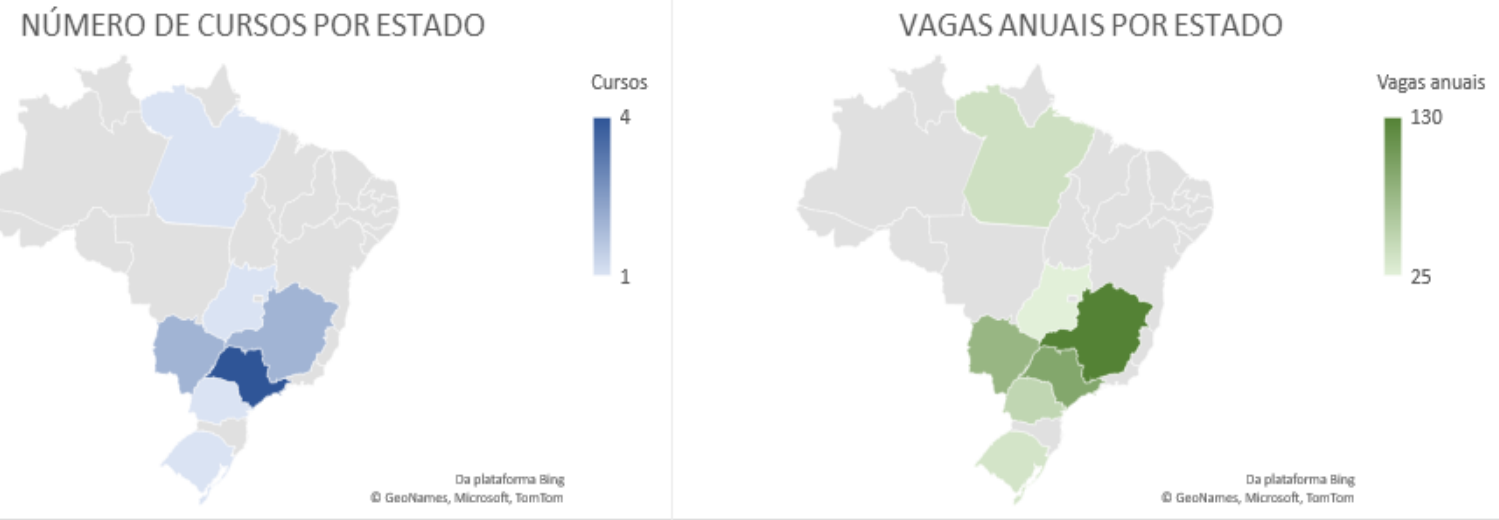

Fonte: Autoria própria.

Por meio da consulta ao banco de dados da plataforma e-MEC, também foi possível analisar os cursos com relação aos seus indicadores oficiais de qualidade, conforme apresentado na Tabela 1.

Tabela 1 - Indicadores de Qualidade de cursos de Engenharia Física no Brasil em 2021.

\begin{tabular}{cccc}
\hline Sigla & ENADE & CPC & Ano \\
\hline UFSCAR & 3 & 4 & 2019 \\
UFRGS & 4 & 4 & 2017 \\
UEMS & 3 & 3 & 2017 \\
UFOPA & 3 & 3 & 2017 \\
\hline
\end{tabular}

Fonte: Adaptado de MEC (2021).

Neste caso, constata-se que apenas quatro dos 12 cursos de graduação foram avaliados por meio do conjunto de indicadores utilizados pelo INEP. Isso é compreensível se considerado que a maior parte dos cursos foi criada ainda não possuíam egressos na ocasião das avaliações, o que inviabilizou a sua realização. Observa-se ainda que, embora todos os cursos com egressos tenham sido submetidos à avaliação do Exame Nacional de Desempenho dos Estudantes (ENADE) no ano de 2017, apenas um dos quatro realizou 
esta avaliação em 2019. A mudança é resultado dos seguintes fatores: (a) não há uma prova específica atrelada à carreira de Engenharia Física no ENADE (uma vez que a área não possui um mínimo de 100 cursos em atividade e 2000 concluintes (INEP, 2015)); (b) ainda existia uma prova de "Engenharia" (sem especificações adicionais) em 2017, opção tradicional dos cursos de Engenharia Física (e de outras Engenharias que não têm prova específica); (c) a prova de "Engenharia" não foi oferecida em 2019, cabendo aos cursos optar por uma das outras provas oferecidas ou por não prestar o Exame e passar pelo processo de avaliação in loco.

Outro indicador de qualidade é o Conceito Preliminar de Curso (CPC) é constituído de oito componentes agrupados em quatro dimensões: desempenho dos estudantes (mensurado a partir do ENADE); valor agregado pelo processo formativo oferecido pelo curso; corpo docente; e percepção discente sobre as condições do processo formativo. Tanto a nota do ENADE quanto o CPC variam em uma escala de 1 a 5 (INEP, 2021). Os resultados obtidos pelos cursos de Engenharia Física podem ser classificados como bons, particularmente considerando-se a inexistência de uma prova específica no ENADE.

Atualmente, os egressos dos cursos recebem o título acadêmico de Bacharel em Engenharia Física e o título profissional de Engenheiro de Controle e Automação, "com as atribuições do art. 1ำ da Resolução $n^{\circ} 427$, de 1999, referentes somente ao controle e automação de equipamentos e processos, e restrição das atividades 01 a 05 do art. 1ㅇa Resolução $n^{\circ}$ 218, de 1973" (CONFEA, 2010). De certa forma, tal restrição equipara os egressos a Tecnólogos (comparem-se CONFEA, 1973 e CONFEA, 1986). Não obstante, um pleito específico de inserção do título de Engenheiro Físico na Tabela de Títulos Profissionais do CONFEA não obteve sucesso (CONFEA, 2014).

\subsection{Levantamentos com egressos}

Dois levantamentos foram encontrados na literatura sobre os egressos dos cursos de Engenharia Física no Brasil. O primeiro foi realizado por FORTES e SANDOVAL (2018) e o segundo faz parte de um projeto de extensão intitulado "ENFI WIKI" realizado por discentes da UFRGS, que coletaram dados de todos os cursos que possuíam egressos (ENFI WIKI, 2020). Como os estudos contém dados diferentes e complementares, ambos serão abordados nessa seção.

No estudo de FORTES e SANDOVAL (2018) foram coletadas 61 respostas válidas, sendo que 52 respondentes declararam ser do sexo masculino (85\%) e 9 do sexo feminino (15\%). Esses dados evidenciam uma discrepância entre os gêneros nas primeiras turmas, indicando a necessidade de iniciativas que visem estimular o ingresso e a permanência de mulheres nesta carreira.

Já em relação ao tempo de conclusão do curso, verifica-se que $45 \%$ terminaram o curso no prazo previsto de cinco anos e 4\% conseguiram obter o diploma em menos tempo, totalizando $49 \%$ de egressos que se enquadravam neste planejamento. Apesar de haver uma retenção de $51 \%$, o levantamento indica que $49 \%$ dos estudantes necessitaram de apenas um ano adicional para se formar, restando apenas $9 \%$ de concluintes em um período superior a seis anos (FORTES e SANDOVAL, 2018). Deste modo, embora a taxa de retenção na amostra possa ser considerada elevada, os números não chegam a ser alarmantes, visto que a análise deve ser contraposta com os dados oficiais e as respectivas taxas de evasão do curso, os quais não foram considerados neste estudo.

FORTES e SANDOVAL (2018) analisaram ainda as áreas de atuação e os cargos ocupados pelos egressos durante o levantamento. Nas áreas de atuação, destacam-se os setores de Pesquisa \& Desenvolvimento (21,3\%), Finanças (18\%) e Consultoria (6,6\%), seguidos por Educação (4,9\%), Desenvolvimento de Produtos (4,9\%), Energia (3,3\%) e 
Tecnologia da Informação (3\%) Vale ressaltar que 18\% dos respondentes trabalhavam como engenheiros em outras modalidades e que $20 \%$ dos respondentes não atuavam em áreas específicas de engenharia. Sendo assim, o estudo indica que o intuito inicial de criar um curso de engenharia com um enfoque direcionado para o desenvolvimento de novas tecnologias obteve sucesso com $80 \%$ da amostra atuando em setores atrelados à engenharia, sendo mais de um quinto na área de Pesquisa e Desenvolvimento (conforme ilustrado na Fig. 2 - esquerda).

A ENFI WIKI (2020) também realizou um levantamento semelhante, contando com 116 respondentes das diferentes universidades que ofertam o curso. $O$ estudo revela que praticamente $90 \%$ dos egressos atuavam em algum setor relacionado à engenharia, distribuídos em áreas de inovação e de alta tecnologia como: computação (25\%), materiais $(15 \%)$, semicondutores (10\%), instrumentação (8\%), mercado financeiro (8\%) e eletromagnetismo (7\%), conforme indicado na Fig. 2 (à direita).

Como seria esperado, a área de Finanças/Mercado Financeiro se destaca em ambos os levantamentos, já que a atuação de engenheiros nas várias vertentes desta área é comum, devido ao desenvolvimento contínuo de habilidades que incluem análise crítica e raciocínio lógico durante a graduação. Outro aspecto que deve ser ressaltado reside na possibilidade de atuação deste profissional em outras áreas de engenharia, comprovando os benefícios adquiridos através de uma boa formação em ciências básicas que permitem essa flexibilidade, também constatada pelas diferentes áreas identificadas nos estudos.

Figura 2 - Áreas de atuação dos Engenheiros Físicos
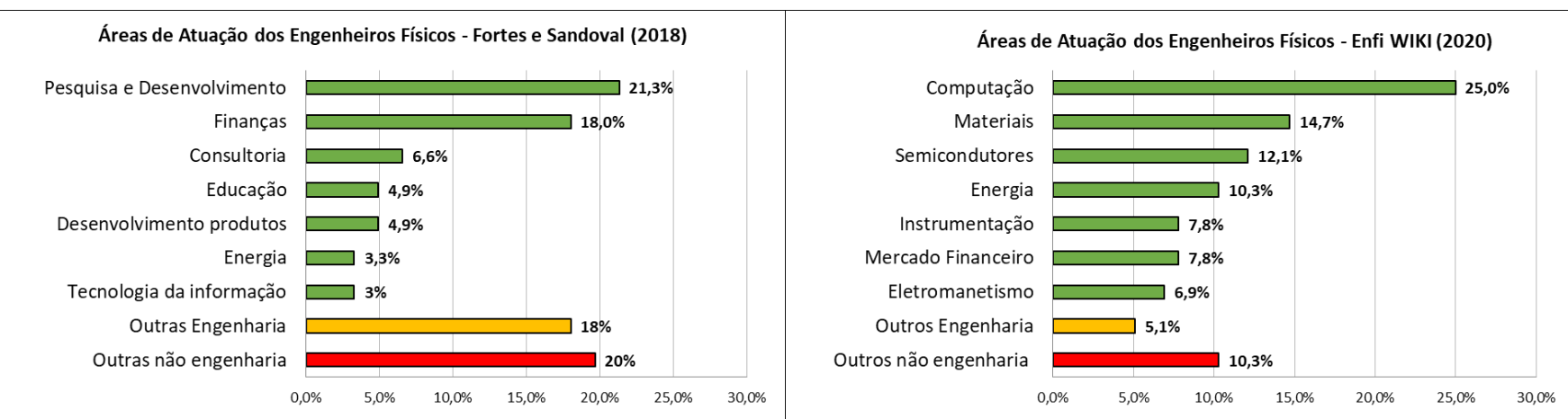

Fonte: Adaptado de Fortes e Sandoval (2018) e ENFI WIKI (2020)

A pesquisa ainda revela dois levantamentos interessantes que buscam relacionar e identificar as fontes de renda dos egressos e o tipo de atividade exercida por eles, conforme apresentado na Fig. 3.

Figura 3 - Fontes de Renda dos egressos

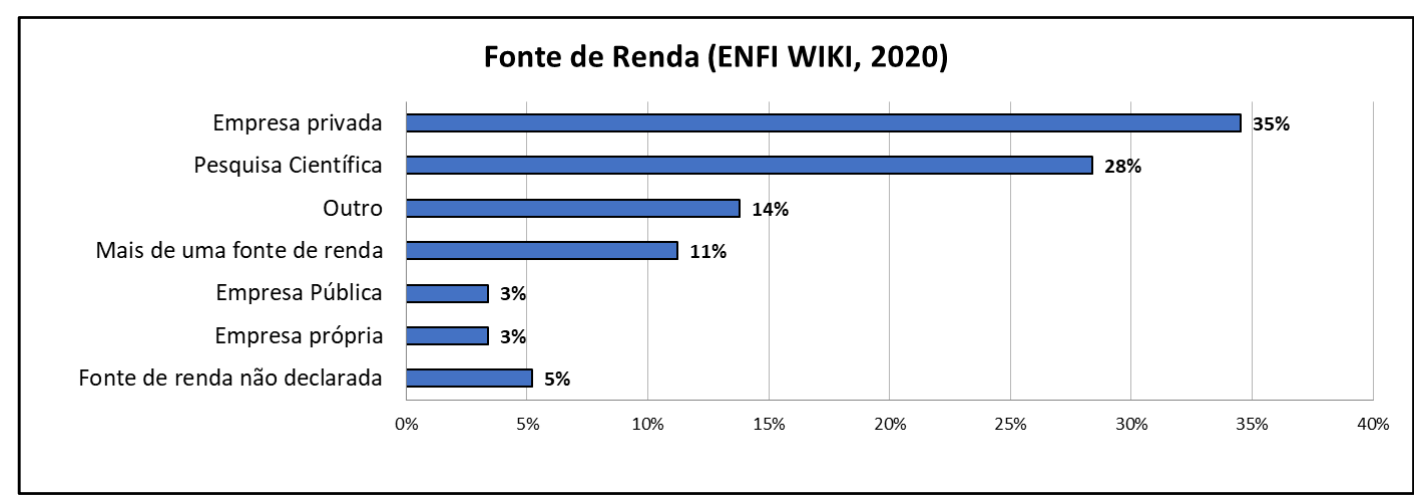

Fonte: Adaptado de ENFI WIKI (2020) 
A maior parte dos egressos da amostra atuavam em empresas privadas $(35 \%)$, Pesquisa Científica (28\%), Empresa Pública (3\%) e Empresa Própria (3\%). Dentre estes, aqueles que possuíam mais de uma fonte de renda $(11 \%)$ superaram em dobro a parcela dos que não declararam a fonte de renda (5\%) (ENFI WIKI, 2020).

Este levantamento também analisou a relação entre a remuneração média mensal e as respectivas atividades, indicando que os melhores índices estão atrelados àqueles que apresentam iniciativas de empreendedorismo, seguidos por professores universitários e profissionais que trabalham em empresas públicas. Em contraste, as remunerações mais baixas estão concentradas nos trabalhos autônomos e nos cargos de professores que não atuam no ensino superior) (ENFI WIKI, 2020).

A Fig. 4 apresenta uma relação entre a faixa de renda mensal média e o tempo decorrido após a formatura. Verifica-se neste estudo que a maior parte dos profissionais recém-formados recebe até três salários-mínimos, indicando que eles não são contratados para trabalhar como engenheiros, uma vez que piso salarial estabelecido pelo Conselho Regional de Engenharia e Agronomia (CREA) é de 8,5 salários-mínimos para uma jornada de 8 horas (CONFEA, 2021; ENFI WIKI, 2020). Esta é uma prática relativamente comum no mercado de trabalho, onde muitos recém-formados são contratados como analistas ou para exercer funções similares.

Figura 4 - Relação entre faixa de renda mensal média e tempo após a formatura

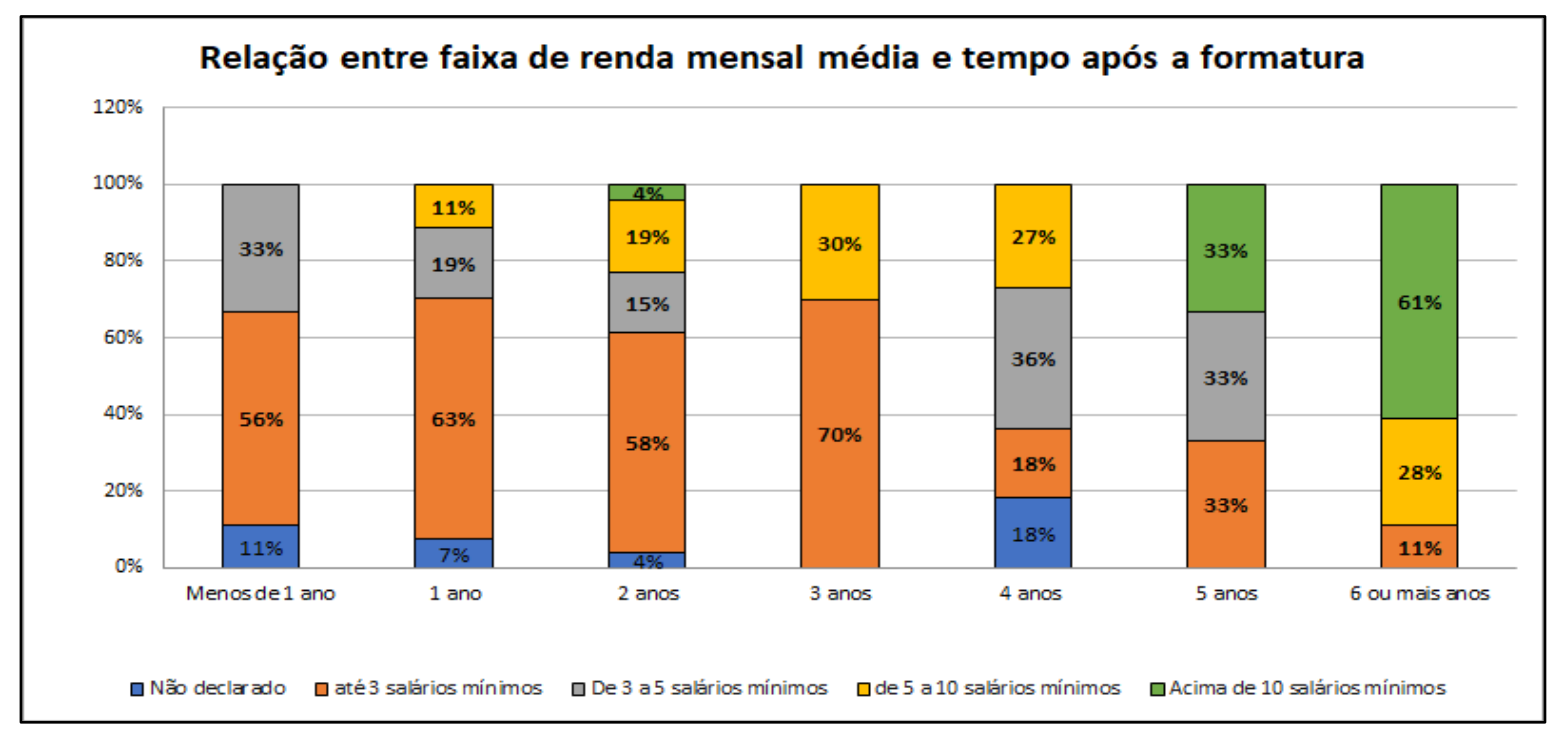

Fonte: Adaptado de ENFI WIKI (2020)

Ao analisar estes dados, consta-se que cerca de $11 \%$ dos profissionais recémformados não ingressaram imediatamente no mercado de trabalho. Por outro lado, a taxa diminui gradativamente até se aproximar de zero em um período de três anos, indicando que estes profissionais normalmente são absorvidos pelas áreas de atuação supracitadas. No quarto ano após a conclusão do curso, contudo, verifica-se que existe um alto índice de egressos que não declararam renda (18\%). Esta relação pode ser compreendida se considerado que boa parte desse contingente conclui uma pós-graduação e ingressa no ensino superior logo após obter o título de mestre ou doutor, o que também pode ser verificado pelo aumento expressivo no quinto e no sexto ano de profissionais com alta remuneração. (ENFI WIKI, 2020).

Outros resultados interessantes que aparecem em ambos os trabalhos correspondem ao levantamento do número de egressos que permaneceram no país, cujos 
dados revelam estatísticas semelhantes. De acordo com os estudos $91,1 \%$ dos respondentes em ENFI WIKI (2020) e 93,5\% em FORTES e SANDOVAL (2018) continuam no Brasil, demonstrando que além de propiciar uma formação de alto nível, a maior parte dos talentos formados são retidos no país.

FORTES e SANDOVAL (2018) também discriminam esses dados no âmbito dos municípios, ressaltando que $23 \%$ dos egressos permaneceram na cidade de São Carlos (SP). O município se apresenta como o segundo destino mais pleiteado pelos egressos, evidenciando o impacto positivo que o curso gera na região e no ecossistema de inovação da cidade, que vêm se desenvolvendo continuamente. Como esperado, a cidade de São Paulo (SP) apresenta-se como o destino que possui o maior número de profissionais (36\%), dado a proximidade geográfica entre estas cidades e a importância econômica da última, tanto em termos da magnitude de seu Produto Interno Bruto (PIB) como na presença de empresas multinacionais. Sugere-se a realização de estudos semelhantes nos diversos cursos que já possuem egressos, a fim de verificar se esse fenômeno pode ser classificado como pontual ou recorrente.

Por fim, o levantamento da ENFI WIKI (2020) questionou aos egressos quais seriam os aspectos que o curso de Engenharia Física propicia como sendo possíveis diferenciais em suas respectivas formações, conforme apresentado na Fig. 5. Os participantes da pesquisa poderiam escolher mais de uma característica, desde que entendessem a relevância do diferencial em questão.

Figura 5 - Possíveis diferenciais dos Engenheiros Físicos

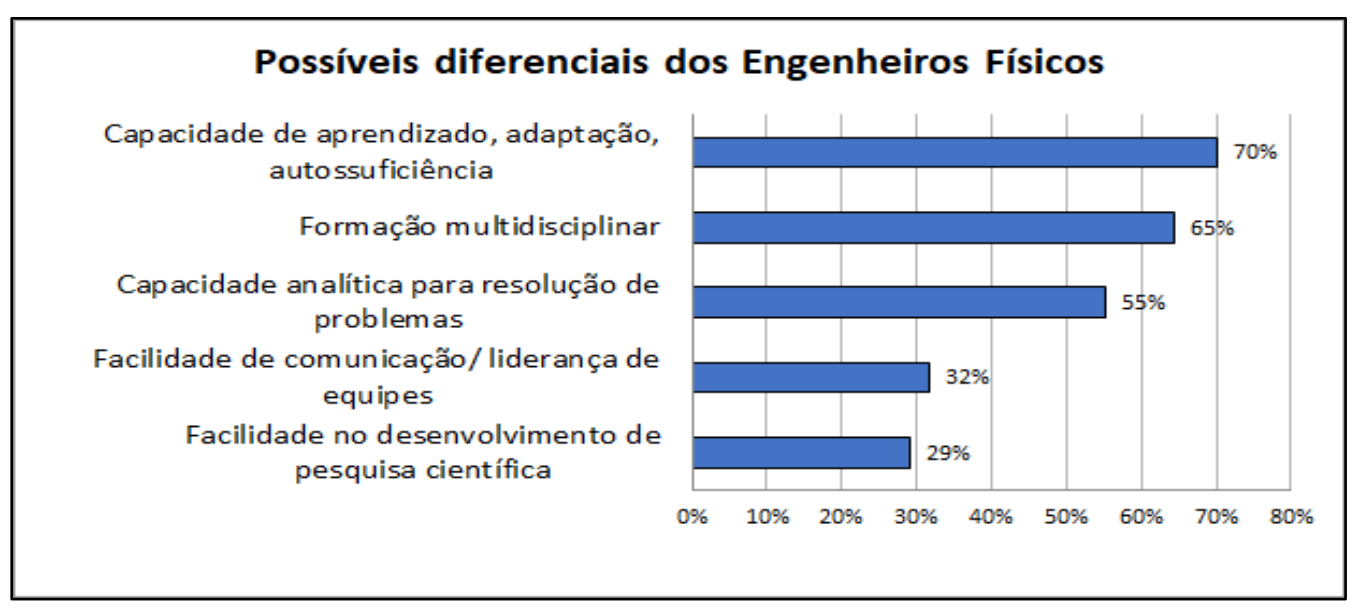

Fonte: Adaptado de ENFI WIKI (2020)

De acordo com a pesquisa, o maior diferencial reside na capacidade de aprendizado $(70 \%)$, também conhecida pela filosofia de "aprender a aprender". Um exemplo deste aspecto se manifesta no propósito de absorver as necessidades da empresa e a busca/proposição de soluções (ARAÚJO-MOREIRA e PÓVOA, 2000) por parte destes profissionais, conforme a proposta de concepção dos cursos. A formação multidisciplinar $(65 \%)$ também se adequa à referida proposta, que mencionava a busca por formar "profissionais multiespecialistas" (ARAÚJO-MOREIRA e PÓVOA, 2000). A capacidade analítica para a resolução de problemas (55\%) e a facilidade de comunicação/liderança de equipes (32\%) - qualidades visadas em todas as engenharias - também foram destacadas. Por fim, a facilidade de atuar no desenvolvimento de pesquisa científica (29\%) encontra-se alinhada com o perfil inovador e a busca por desenvolvimento de soluções (NASSAR et. al., 2008; KAMASSURI et al., 2018). 


\subsection{A primeira Pós-graduação}

Outro passo importante para o crescimento e a consolidação da carreira no Brasil foi alcançado em 2018, contemplando a região Nordeste com a aprovação da criação do primeiro curso de Pós-Graduação em Engenharia Física, na Universidade Federal Rural de Pernambuco (UFRPE).

O programa oferece duas áreas de concentração: materiais e optoeletrônica. A primeira foca no desenvolvimento, caracterização e aplicação de materiais e possui caráter interdisciplinar, com linhas de pesquisa direcionadas para materiais nanoestruturados e aplicações ambientais, energéticas e industriais. Já a segunda visa agregar competências em temas complementares das Engenharias e da Física para oferecer uma formação generalista sólida, com pesquisas que relacionam o estudo e o desenvolvimento de sistemas ópticos, opto-eletrônicos, eletrônicos e/ ou explorando suas dinâmicas através de três linhas de pesquisa, a saber: metrologia e instrumentação, espectroscopia coerente e óptica não linear, e controle e dinâmica não linear (PPGENGFIS, 2019). Não foram encontradas dissertações publicadas até a submissão deste artigo; contudo, 19 projetos estavam em andamento e 39 discentes inscritos no programa, evidenciando uma procura consideravelmente alta para um programa de pós-graduação relativamente novo.

\section{$5 \quad$ CONCLUSÕES}

O bacharelado em Engenharia Física foi criado em 1999 na Universidade Federal de São Carlos (UFSCar) e iniciou suas atividades no ano de 2000. Atualmente, a carreira é ofertada em 12 cursos de graduação em instituições públicas distribuídas nas regiões Sul, Sudeste, Centro-Oeste e Norte, além do programa de pós-graduação criado pela Universidade Federal Rural de Pernambuco (UFRPE), na região Nordeste. Neste cenário, São Paulo é o estado que oferece mais opções com quatro universidades, seguido por Minas Gerais e Mato Grosso do Sul (ambos com duas). Por sua vez, Minas Gerais é o primeiro estado na lista de oferta de vagas, com São Paulo e Mato Grosso do Sul ocupando respectivamente a segunda e terceira posições.

Os dois principais levantamentos discutidos neste trabalho (FORTES e SANDOVAL (2018) e (ENFI WIKI, 2020) apresentam indicadores com informações relevantes sobre o perfil dos egressos dos cursos de Engenharia Física no país. O primeiro estudo foi baseado em uma consulta realizada com profissionais de todas as turmas que se formaram na UFSCar, enquanto o segundo foi elaborado com dados obtidos de egressos oriundos de todas as instituições no país.

FORTES e SANDOVAL (2018) revelam que mais da metade dos egressos permaneceu no estado de São Paulo (SP), concentrando-se majoritariamente na capital e no município de São Carlos (SP). Já ENFI WIKI (2020) aponta que a quase totalidade dos recém-formados adquirem ao menos uma fonte de renda própria em um período de três anos após a conclusão do curso, sugerindo que uma parcela significativa deste contingente possui a tendência de cursar uma pós-graduação.

Os levantamentos contêm padrões semelhantes em determinados aspectos. Ambos os estudos mostram que o Brasil retém mais de $90 \%$ destes profissionais que, por sua vez, estão inseridos em cargos de empresas e instituições de ensino e pesquisa distribuídas em todas as regiões do país, atuando principalmente nos setores de desenvolvimento de novas tecnologias, inovação e finanças. Neste contexto, nota-se que a maioria dos recémformados recebe menos do que o piso salarial estabelecido pelo Conselho Regional de Engenharia e Agronomia (CREA). Além disso, constata-se a necessidade de fomentar iniciativas que visem estimular o ingresso e a permanência de mulheres nesta carreira. 
Embora os títulos acadêmicos de Bacharel em Engenharia Física e profissional de Engenheiro de Controle e Automação sejam atribuídos a esta carreira, há um consenso entre os autores de que o curso de Engenharia Física deve ser enquadrado em uma categoria específica. O desempenho dos estudantes no ENADE também deve ser ressaltado (já que não há uma prova específica atrelada à área), e os resultados obtidos pelos cursos de Engenharia Física podem ser classificados como satisfatórios. Com base nos dados e nas discussões apresentadas neste trabalho, pode-se afirmar que a filosofia de "aprender a aprender" e a proposta de formar profissionais multiespecialistas permanecem até hoje como os pilares que definem a essência desta carreira.

Ainda analisando as duas amostras, verifica-se que durante as primeiras duas décadas do curso os egressos obtiveram sucesso na inserção no mercado de trabalho em diferentes áreas, especialmente naquelas as quais a formação visava contemplar, com destaque para Pesquisa \& Desenvolvimento, empresas de tecnologia (computação, semicondutores, instrumentação, eletromagnetismo, materiais), desenvolvimento de produtos e mercado financeiro.

Com as novas áreas intensivas em conhecimento assumindo cada vez mais importância nos mercados globais - especialmente aquelas que se baseiam em tecnologias disruptivas (como computação quântica, energias renováveis, fusão nuclear, dentre outras) - a busca por um profissional que domine as ciências básicas e consiga empregar as novas tecnologias no ramo da engenharia tende a aumentar. De modo semelhante, além do desenvolvimento de tecnologias específicas, é necessário buscar a integração entre esses conhecimentos e habilidades, sendo imprescindível a formação de profissionais multiespecialistas.

Por fim, está em andamento a revisão dos Projetos Pedagógicos de Curso (PPCs) para adequar os PPCs às novas Diretrizes Curriculares Nacionais do Curso de Graduação em Engenharia e à curricularização da Extensão (CNE, 2018; 2019). Com isso, espera-se revisitar a criação do título profissional de Engenheiro Físico junto ao CONFEA, assim como tornar a aplicação de conhecimentos teóricos avançados em projetos de engenharia cada vez presentes no cotidiano.

\section{Agradecimentos}

Agradecemos a todos os docentes, discentes, técnicos-administrativos, apoiadores, egressos e seus familiares que confiaram na ideia do curso de Engenharia Física e contribuíram para a construção e consolidação desta carreira ao longo das duas primeiras duas décadas no Brasil.

\section{REFERÊNCIAS}

ARANTES, Eduardo Marques. A reengenharia do ensino das engenharias: da construção do discurso oficial à produção de reformas curriculares.2002. Tese (Doutorado) - Programa de Pós-Graduação em Educação. Universidade Federal de Minas Gerais, Belo Horizonte, 2002. Disponível em: https://repositorio.ufmg.br/handle/1843/HJPB-5MAKWH. Acesso em: 19 de abril de 2021.

ARAÚJO-MOREIRA, Fernando M.; PÓVOA, José M. O primeiro curso de Engenharia Física do Brasil: um projeto já concretizado. In: XXVIII Congresso Brasileiro de Educação em Engenharia (COBENGE), 2000, Ouro Preto. Anais. Ouro Preto. 
ARAUJO-MOREIRA, F.M., Engenharia Física: a carreira do novo milênio; Guilen e Andrioli Gráfica \& Editora, ISBN 978-85-88533-91-2; 2014.

CONSELHO NACIONAL DE EDUCAÇÃO (CNE). Resolução CNE/CES № 7, de 18 de dezembro de 2018.2 Disponível em: http://portal.mec.gov.br/index.php?option=com docman\&view=download\&alias=104251rces007-18\&category slug=dezembro-2018-pdf\&Itemid=30192. Acesso em: 04 de maio de 2021.

Resolução no 2, de 24 de abril de 2019. Diretrizes Curriculares Nacionais do Curso de Engenharia. Brasília, DF. Disponível em: https://www.in.gov.br/web/dou//resolu\%C3\%87\%C3\%830-n\%C2\%BA-2-de-24-de-abril-de-2019-85344528. Acesso em: 27 de janeiro de 2020.

CONSELHO FEDERAL DE ENGENHARIA E AGRONOMIA (CONFEA). Resolução № 218, de $1973 . \quad$ Disponível em: https://normativos.confea.org.br/ementas/visualiza.asp?idEmenta=266. Acesso em: 04 de maio de 2021.

Resolução № 313, de 1986. Disponível em: https://normativos2.confea.org.br/ementas/visualiza.asp?idEmenta=361. Acesso em: 04 de maio de 2021.

Decisão Plenária № 0575/2010. Disponível em: https://normativos.confea.org.br/ementas/visualiza.asp?idEmenta=44855. Acesso em: 04 de maio de 2021.

Decisão Plenária № 1917/2014. Disponível em: https://normativos.confea.org.br/ementas/visualiza.asp?idEmenta=55502. Acesso em: 04 de maio de 2021.

Salário

Mínimo

Profissional.

Disponível

em: https://www.confea.org.br/profissional/salario-minimo-profissional. Acesso em: 04 de maio de 2021.

ENFI WIKI. Disponível em: https://enfiwiki.wixsite.com/enfiwiki. 2020. Acesso em: 20 abril de 2021.

FORTES, Raphael. I. G.; SANDOVAL, Rafael D. Um levantamento da atuação dos Engenheiros Físicos da UFSCar. In: XIII Simpósio Brasileiro de Engenharia Física e I Congresso Internacional de Engenheiros Físicos, 2018, Foz do Iguaçu.

INSTITUTO NACIONAL DE ESTUDOS E PESQUISAS EDUCACIONAIS ANÍSIO TEIXEIRA (INEP). Nota Técnica $\mathrm{N}^{\circ}$ 37/2015. Disponível em: https://download.inep.gov.br/educacao superior/enade/legislacao/2015/nota tecnica \%20 n0372015 avaliacao de teologia enade\%202015.pdf. Acesso em: 04 de maio de 2021.

INSTITUTO NACIONAL DE ESTUDOS E PESQUISAS EDUCACIONAIS ANÍSIO TEIXEIRA (INEP). Indicadores de Qualidade da Educação Superior. Disponível em: https://www.gov.br/inep/pt-br/areas-de-atuacao/pesquisas-estatisticas-e- 
indicadores/indicadores-de-qualidade-da-educacao-superior. Acesso em: 04 de maio de 2021.

KAMASSURY, Jorge K. S.; DUARTE, W. G.; ROMANO, Marcel A. de A.; BATISTA, Jussara V. S.; FURTADO NETO Alírio T. Engenharia Física: inovação, formação generalista e os desafios no cenário amazônico. In: XLV Congresso Brasileiro de Educação em Engenharia (COBENGE), 2017, Joinville. Anais. Joinville. Disponível em:

MINISTÉRIO DA EDUCAÇÃO - MEC: Sistema e-MEC. Disponível em: https://emec.mec.gov.br/. Acesso em: 10 de abril de 2021.

MONTGOMERY, D. C.; RUNGER, G. C. Estatística aplicada e probabilidade para engenheiros. 6. Ed. Rio de Janeiro: LTC. 2016.

NASSAR, Antonio. B.; SOBRINHO, Carlos L. da S. S.; ALMEIDA, José F; BASSALO, José M. F. de SOUZA, Nelson P. C. Uma engenharia para a Amazônia. In: XXXVI Congresso Brasileiro de Educação em Engenharia (COBENGE), 2008, São Paulo. Anais. São Paulo.

PÓVOA, José M.; ARAÚJO-MOREIRA., Fernando M. A. Engenharia Física na inovação tecnológica regional. In: XXXI Congresso Brasileiro de Educação em Engenharia (COBENGE), 2003, Rio de Janeiro. Anais. Rio de Janeiro.

PROGRAMA DE PÓS-GRADUAÇÃO EM ENGENHARIA FÍSICA. Disponível em: http://www.ppengfis.ufrpe.br/. Acesso em: 19 de abril de 2021.

ST. JOHN, R. M. Engineering physics - a unique field. The Physics Teacher, v. 14, p. 486, 1976. Disponível em: https://doi.org/10.1119/1.2339465. Acesso em: 04 de maio de 2021.

\title{
INSTRUCTIONS FOR PREPARATION AND SUBMISSION OF WORKS TO THE SCIENTIFIC COMMITTEE OF XLIX BRAZILIAN CONGRESS OF ENGINEERING EDUCATION - COBENGE 2021
}

\begin{abstract}
This article analyzes the consolidation of the Engineering Physics career in Brazil over the first two decades. We reviewed the background and the motivations that inspired the creation of this course and its direction towards a transdisciplinary training. We also analyze the evolution of this career based on the available information on the area and in two studies that address the performance of graduates in the country. Finally, we discuss the limitations and future studies concerning the prospects of the Engineering Physics career in Brazil, proving that the philosophy of "learning to learn" and the proposal to educate multispecialist professionals have been successfully achieved.
\end{abstract}

Keywords: Engineering Physics; Science; Career; Transdisciplinary; Graduate 